Ife Journal of Science vol. 20, no. 3 (2018)

\title{
STUDIES ON THE PREVALENCE AND INTENSITIES OF GASTROINTESTINAL HELMINTHS INFECTIONS AMONG POST-PRIMARY SCHOOL STUDENTS IN OSOGBO METROPOLIS, SOUTHWESTHERN NIGERIA
}

\author{
$*^{1}$ Rufai, A. M., ${ }^{1}$ Saliu, N. A., ${ }^{2}$ Adefioye, O. A. \\ 'Zoological Unit, Department of Biological Sciences, College of Science, Engineering and Technology, Osun State \\ University, Osogbo, Nigeria \\ ${ }^{2}$ Parasitology unit, Ladoke Akintola Teaching Hospital, Ladoke Akintola University, Osogbo \\ *Author for Correspondence. E-mail: taiworuf@yahoo.co.uk; akinlabi.rufai@uniosun.edu.ng
}

(Received: $13^{\text {th }}$ September, 2017; Accepted: $11^{\text {th }}$ November, 2017)

\section{ABSTRACT}

\begin{abstract}
There is a deficit of published data on the prevalence and intensity of intestinal parasitic infections in Osogbo metropolis, although there exist some reports for few of the local government areas of Osun state. Post primary school students are at high risk of acquiring gastrointestinal parasitic infections in Osogbo metropolis. A total of one hundred and fifty fecal samples were examined microscopically from post primary school students aged $9-$ 18. Direct microscopic examination, centrifugation floatation and sedimentation techniques were used to examine fecal samples while Kato-katz technique was used to determine the intensity of infection. Ascaris lumbricoides, Strongyloides stacoralis and Hookworm were the most common intestinal helminths recovered. $A$. lumbricoides formed the bulk of the infections with prevalence rate of $124(91.9 \%)$ followed by S. stacoralis 8 $(6.0 \%)$ and Hookworm, $3(2.2 \%)$. Specific factors related to the environments that were examined included water source, toilet or latrine use and refuse disposal Multiple infection of two - three parasite combinations were common, A. lumbricoides - Hookworm combination being the most common. Analysis of the data on the basis of sex revealed a significant difference $(\mathrm{P}<0.05)$ in the overall incidence of infections between male $(75.6 \%)$ and female $(84.8 \%)$. The maximum infection was observed in younger age groups compared to adults $(\mathrm{P}<0.05)$. Infections were greater among households drinking water from stream followed by well water and those using pit/open field for toilets. This report recommends that good drinking water coupled with adequate toilet facility and deworming programs be integrated in private and public schools as well as promotion of healthier diets as most effective tools in controlling helminthes infection among school children.
\end{abstract}

Keywords: Prevalence, Intensity, Intestinal helminths, Post-primary students, Risk factors

\section{INTRODUCTION}

Intestinal helminths parasites cause significant morbidity and mortality throughout the world, particularly in underdeveloped countries where there is limited access to safe drinking water, sanitation, and nutrition (WHO, 1996). It constitutes major health problems, especially in the tropical and sub- tropical regions (Damen, et al., 2011). In developing countries, it is estimated that about 3.5 billion people are affected, and that 450 million are ill as a result of these infections, the majority being children (Teklu et al., 2013). In other estimation, about one quarter of the world's population is infected and about $80 \%$ of all deaths annually are due to infections by intestinal parasites in developing countries (Faten, 2008). Rashid et al. (2011) attributed the high prevalence of these infestations to poverty, poor environmental hygiene, and impoverished health services. Intestinal parasite infestations are more frequent among school age children, and they tend to occur in high intensity in this age group (Ogbe et al., 2002). Since intestinal parasitic infections are associated with poor socioeconomic class and unsanitary environments, people living in such conditions are at risk of exposure. Intestinal parasites populate the gastro- intestinal tract. The major groups of parasites include protozoans and parasitic worms (Helminths). The main intestinal parasites that infect human are Ascaris lumbricoides, Trichuris trichiura Entamoeba histolytica, Balantidium coli, Giardia lamblia, Isospora belli, Cryptosporidium species, Taenia saginata, Taenia solium, Hymenolepsis nana, Dipyllidium caninum, Diphylobotbrium latum, Fasciolapsis buski, Metagonimu syokogawai, Heterophyses spp, Hook worms, Strongyloides stercoralis and Schistosoma mansoni (Rufai and Awi-waadu, 2006). These parasites are among the most prevalent human infections affecting approximately one quarter of the world's populations, mainly school children due to their poor hygienic nature or poor sanitary conditions coupled with their voracious eating habits (WHO, 1996). Parasites can get into the intestine through the mouth from uncooked 
or unwashed food, contaminated water or hands or by skin contact with larva-infested soil. People can also become infected with intestinal parasites if they have mouth contact with the genital or rectal area of a sexual partner who is infected (e.g. oral sex or anal-oral contact). When the organisms are swallowed, they move into the intestine, where they reproduce and cause disease. In some people, intestinal parasites do not cause any symptoms or the symptoms may come and go. Common signs and complaints include coughing, cramping, abdominal pain, bloating and diarrhoea. In more serious infections diminished sex drive, skinitching, fever, nausea, vomiting or bloody stools may occur. Some parasites also cause low red blood cell count (anemia) and some travel from the lungs to the intestine or vice versa and other parts of the body. Therefore, laboratory tests are necessary to determine their cause. However, because many parasitic infections especially those of helminths origin are usually asymptomatic or produce only mild symptoms, they are often neglected until serious complications or chronic clinical pictures appear (WHO, 1996). It is recognized that certain factors play important roles which include: the strain and number of the parasites, age and level of immunity at the time of infestation, immune responses to the infestations, presence of co-existing diseases or conditions which reduce immune responses, malnutrition undertone due to iron deficiency, folic acid and protein deficiency. These could occur singly or in combination with other causative agents (McGregor et al., 1996). Intestinal parasites are regarded as important public health problem in tropical Africa (Odutan et al., 1974). The presence of these parasites in asymptomatic carriers has been a major source of infection to susceptible hosts, hence compounding the problem. In endemic countries, intestinal infections are most prevalent in rural communities, peri-urban settings and urban slums (Fashuyi, 1983). Although, intestinal parasites could be considered as major problem in rural settlements in Nigeria due to their poor socio-economic status and lack of basic amenities such as water, toilets facilities etc. many urban areas of the country are still exposed to intestinal parasitic infections due to level of sanitation and personal hygiene which predisposes them to cockroach and rat invasions. Rufai and Olagunju, (2017) have implicated rats in domestic and market areas in the prevalence of intestinal helminths. Adeleke et al., (2012) in another study attributed prevalence of intestinal helminths to cockroach invasion. Previous surveys had shown variations in the prevalence and distribution of gastro-intestinal parasites among inhabitants of different locations in Nigeria (Udonsi et al., 1996; Mafiana et al., 2000; Awi-Waadu, 2005; Anosike et al., 2006; Rufai and Awi - Waadu, 2006) with the additional challenge of identifying the most vulnerable group requiring immediate deworming programs with consideration on the risks-benefits ratio (SamWobo et al., 2006). Epidemiological research works on intestinal parasites in Osun state is very scanty and the few available were done in the rural areas (Adefioye et al., 2011; Adeleye et al., 2015). None exist in the study area. Previous intestinal parasite studies undertaken in Osogbo have focused on cockroaches or rats as possible vectors of intestinal parasites (Adeleke et al., 2012; Rufai and Olagunju, 2017). Cockroach and rat invasion is a result of poor sanitation. Socioeconomic status of most residents in Osogbo conform to low standard using a validated poverty index which was calculated using the United Nation's unsatisfied basic needs measurement, based on housing, sanitation, education, and employment (UNDP, 2006). In Nigeria, many intervention schemes which were attempted to control these infections did not yield much success, many are still heavily infected particularly children (Ijagbone and Olagunju, 2006). In view of the negative socio-economic impact of these parasitic infections on infected humans, efforts could be made to elucidate their epidemiological state among students. Therefore this study is an attempt to provide information on the prevalence of intestinal helminths among post primary school students in Osogbo metropolis- to know the intensity and types of intestinal parasites infection that are common among the post - primary school students. This is in other to draw the attention of government authority to the rate of infection so as to eradicate the problem among the children.

Specific factors related to the environment that was examined included water source, toilet or latrine use and refuse dumps. Parasitic worms are among the most common cause of chronic infection in humans and it has been reported that 
gastro- intestinal parasites (GIT) could affect the academic performances of children in developing countries (Raj et al., 1997). Studies have shown that the most vulnerable group to intestinal parasitic infections are children because they harbour heavy infections due to their vulnerability to nutritional deficiencies (WHO, 1992). Infections with Ascaris, hookworms and Trichuris trichura, have been associated with anaemia (Casapia et al., 2007; Omorodion et al., 2012; Somphou, et al., 2015). Montressor et al., (2002) Asaolu and Ofoezie, (2003) and Awasthi et al., (2013) had all attributed poor environmental hygiene and poor socioeconomic conditions among the major factors that promote the survival and transmission of GIT parasites. Faecal contamination of food or water and use of soil contaminated with faeces as fertilizers are the common routes of transmission of intestinal parasites. Consuming food from street vendors is associated with enhanced risk. Young children are at particular risk because they have a propensity to touch multiple objects and to put them in their mouths. Children are less selective in sources and types of food ingested and their gastrointestinal immunity is not as robust as adults (Udonsi et al., 1996). In Nigeria, more than $90 \%$ of this age group (0-18) are either in preschool, primary or secondary school (Ogbe et al., 2002). This attempt is to determine the prevalence and intensity of gastrointestinal helminths infections in post primary school students in Osogbo as an integral part of a proposed work on the current status of the prevalence and intensity of helminth infections in Osogbo. This is with the aim of advancing appropriate recommendations in reducing the burden of infection and its possible consequences.

\section{MATERIALS AND METHODS}

Study Area: This is a school-based cross-sectional study that was carried out at two government schools in Osogbo in Osun State southwestern Nigeria. The schools were Muslim Middle School 1 and Muslim Middle School 2. The study was undertaken from February 2017 to March, 2017. Stool samples were collected from different age groups. Study subjects were selected using a systematic random sampling method. Data were gathered through direct interview by using a pretested questionnaire. School 1 was located at about $10 \mathrm{~km}$ away from the government house, Osogbo while school 2 was located $6 \mathrm{~km}$ from the center of Osun Osogbo shrine. Each school had a population of about 700 and 950 students respectively.

Ethical Consideration: Ethical permission and clearance were obtained from Osun State Ministry of Health and Ministry of Education Ethical Committee, Osogbo, Nigeria. Permissions to screen the students were sought from the parents and the schools' principals. Informed consents were given by individual participants after explaining the objectives, possible outcome and benefits of the research.

Samples: One hundred and fifty (150) fecal samples were taken from individuals of different age groups and sexes. Added information sought included water source, toilet or latrine use, household construction and demographic data such as sex, age, and name of subject were recorded.

\section{Laboratory Analysis}

Laboratory stool analysis was performed in the Biology laboratory of the Biological Sciences Department of Osun State University Osogbo, using direct microscopic technique and normal saline method in identification of the eggs. The stool specimens were collected in labeled plastic without preservatives and examined in less than two hours. Kato-Katz techniques were used on the positive ones to determine the intensity of infection. During the procedure, the glass slide was labeled with the sample number and the plastic template was placed on top of it, small amount of the faecal sample was placed on a newspaper and a piece of nylon screen was placed on top. A spatula was used to scrape the sieved faecal material through the screen to remove the debris. The sieved faeces was used to fill the hole in the template, this was properly leveled to remove air bubbles. The excess faeces were removed from the template. The template was carefully lifted and placed in a bucket of water mixed with concentrated detergent for reuse. A piece of cellophane that was soaked overnight in methylene blue glycerol solution was placed over the faecal sample. A clean slide was placed over the top and pressed downward to spread the faeces in 
a circle. The slide was gently removed by sliding it sideway to avoid separating the cellophane strip. The slide was then placed upwards. The slide was placed under a microscope and examined systematically in zigzag pattern to view the whole area. The type of each egg and species was noted and recorded alongside the sample number. Finally, the number of eggs was multiplied by the appropriate number to give the number of eggs per gram (epg) - the standard measurement to assess the intensity of infection. This is as previously described by WHO (1992). The intensity of infections was categorized as heavy, moderate and light. Subjects with pathogenic parasitic infection on stool exam were offered treatment with antihelminth medications per the local standard of care.

\section{Statistical Analysis:}

The data obtained from this study were subjected to odd ratio analysis using InStat statistical package. The difference was considered statistically significant when $\mathrm{P}<0.05$.

\section{RESULTS}

Of a total of 150 faecal samples examined for gastrointestinal parasites among post-primary school students in Osogbo local government area of Osun State, 135 students representing 90\% were positive for one or more parasite species (Table 1).

Table 1: Prevalence of Intestinal Parasites in two (2) Post-primary schools in Osogbo metropolis

\begin{tabular}{llll}
\hline School & $\begin{array}{l}\text { Number } \\
\text { Examined/School }\end{array}$ & $\begin{array}{l}\text { Total No infected } \\
\text { / School }\end{array}$ & $\begin{array}{l}\text { Prevalence } \\
\mathbf{( \% )}\end{array}$ \\
\hline Muslim grammar School 1 (MGS 1) & 75 & 72 & 96.0 \\
Muslim Grammar School 2 (MGS 2) & 75 & 63 & 84.0 \\
\hline
\end{tabular}

Prevalence of intestinal helminths in relation to intensity of the parasites was determined in 85 infected samples processed for Kato-katz techniques to determine the intensity of infections, a total of 1082 eggs were counted of which 1054 were recorded for Ascaris lumbricoides,
19 eggs for Strongiloides stercoralis and 9 eggs for Hookworm. The egg number per gram faeces (EPG) showed intensity of Ascaris lumbricoides as (97.4\%) followed by Strongyloides stercoralis $(1.8 \%)$ while Hookworm had the least intensity of $(0.8 \%)$ (Table 2).

Table 2: Intensity-specific Prevalence of Intestinal Parasites among Randomly Selected Post-primary School Students in Osogbo Metropolis.

\begin{tabular}{llc}
\hline Parasite & No of eggs counted (by 24 & Prevalence \\
& EPG Kato-katz standard) & \\
\hline Ascaris lumbricoides & 25296 & 97.4 \\
Strongyloides stercoralis & 456 & 1.8 \\
Hookworm & 216 & 0.8 \\
Total & 25968 & \\
\hline
\end{tabular}

The prevalence of intestinal helminthes parasites in the sampled population in relation to sex of the students showed that 64 were males and 86 were females from a total of $135(90 \%)$; A. lumbricoides, had $59(92.2 \%)$ males and $76(88.8 \%)$ females; 8 $(5.3 \%)$ for S. strongiloides and $5(7.8 \%)$ males and 3
(3.5\%) females; 3 (2.0\%) for Hookworm 2 (2.3\%) and $1(1.6 \%)$ respectively (Table 3$)$. The only uninfected child was a 9 year old female. Percentage infection rates showed that there was statistically significant association between the sexes and prevalence rate. 
Table 3: Sex-Specific Prevalence of Intestinal Parasites among Randomly Selected Post-Primary School Students in Osogbo Metropolis.

\begin{tabular}{llll}
\hline Parasite/Sex & No Examined & No Infected & Prevalence \% \\
\hline Ascaris lumbricoides & & & \\
Male & 64 & 59 & 92.2 \\
Female & 86 & 76 & 88.8 \\
Total & 150 & 135 & 90.0 \\
Strongyloides stercoralis & & & \\
Male & 64 & 5 & 7.8 \\
Female & 86 & 3 & 3.5 \\
Total & 150 & 8 & 5.3 \\
Hookworm & & & \\
Male & 64 & 1 & 1.6 \\
Female & 86 & 2 & 2.3 \\
Total & 150 & 3 & 2.0 \\
\hline
\end{tabular}

Age specific prevalence of parasites showed that students who are in the $9-11$ year age group had the highest prevalence of 59 (93.7\%), age group 12-14 year had 35 of the 40 students examined infected with $85.5 \%$ prevalence and age group $15-17$ year had the least with 41 infected out of 47 examined with prevalence rate of $82.7 \%$ (Table 4).

Table 4: Age-Specific Prevalence of Intestinal Parasites among Randomly Selected Post-Primary School Students in Osogbo Metropolis

\begin{tabular}{llll}
\hline Age group (Years) & $\begin{array}{l}\text { No. } \\
\text { Examined }\end{array}$ & $\begin{array}{l}\text { No. positive } \\
\mathbf{( \% )}\end{array}$ & $\begin{array}{l}\text { No negative } \\
\mathbf{( \% )}\end{array}$ \\
\hline $9-11$ & 63 & $59(93.7)$ & $4(6.3)$ \\
$12-14$ & 40 & $35(87.5)$ & $5(7.9)$ \\
$15-17$ & 47 & $41(87.2)$ & $6(9.5)$ \\
Total & 150 & $135(90)$ & $15(10)$ \\
\hline
\end{tabular}

Three species of parasites were identified during the study; Ascaris lumbricoides; Strongyloides stercoralis and Hookworm. Ascaris lumbricoides was recorded in 124 students representing $91.9 \%$ of the study population, followed by Strongyloides stercoralis 8 $(6 \%)$, Hookworm $3(2.2 \%)$. Of the total students examined, $10(7.5 \%)$ had double infections while $125(92.6 \%)$ had single infection. Double infection involving a combination of Ascaris lumbricoides/Strongyloides stercoralis had the highest prevalence, $8(5.9 \%)$ (Table 5).

Table 5: Single and Double Intestinal Parasites Infection among Randomly Selected Post-Primary School Students in Osogbo Metropolis.

\begin{tabular}{lll}
\hline Single Infection & No Infected & Prevalence \\
\hline Ascaris lumbricoides & 121 & 89.6 \\
Strongyloides stercoralis & 2 & 1.6 \\
Hookworm & 2 & 1.5 \\
Total & 125 & 92.6 \\
Double Infection & & \\
Ascaris lumbricoides/ Hookworm & 2 & 1.5 \\
Ascarislumbricoides/ Strongyloides stercoralis & 8 & 5.9 \\
Total & 10 & 7.5 \\
\hline
\end{tabular}


The responses of students to the questionnaire administered and the results of statistical analysis showed some association between the various epidemiological variables and the infection (Table 6). Prevalence of intestinal parasitic infections according to water source showed that the prevalence was higher in students who used streams as their source of drinking and bathing and least in those that used either bore-hole or tap water as sources of drinking or bathing. Out of 94 students who indicated that they use streams, 89 $(94.7 \%)$ tested positive for intestinal parasites, 40 respondents that use well water had $33(82.5 \%)$ positive cases while out of 16 respondents that use boreholes, $13(81.3 \%)$ had positive cases.
Prevalence of intestinal helminth infections according to type of toilet showed that individuals that used open field defecation had higher prevalence than those that used pit latrine and water closet. Those that responded that they use open field defecation had $33(91.7 \%)$ positive cases out of 36 respondents and $44(89.8 \%)$ out of 49 for pit latrine and water closet $58(89.2 \%)$ out of 65 respondents.

Prevalence of intestinal helminthes infections according to how they take anti-helminthic drug showed that of 121 respondents, $117(96.7 \%)$ had positive cases. Those students that do not take anti-helminthic drugs before were 18 (62.1\%) out of 29 respondents.

Table 6: Relationships between Various Epidemiological Variables and the Intestinal Parasitic Infections among Post-Primary School Students in Osogbo Metropolis.

\begin{tabular}{llll}
\hline Other Risk Factors & $\begin{array}{l}\text { No. } \\
\text { Examined }\end{array}$ & No positive (\%) & $\begin{array}{l}\text { No negative } \\
\mathbf{( \% )}\end{array}$ \\
\hline Water source & 40 & $33(82.5)$ & $7(17.5)$ \\
Well water & 16 & $41(87.2)$ & $3(18.8)$ \\
Borehole & 94 & $89(94.7)$ & $5(5.3)$ \\
Stream & 150 & $135(90.0)$ & $15(10.0)$ \\
Total & & & \\
Toilet Type & 65 & $58(89.2)$ & $7(10.8)$ \\
Water closet & 36 & $33(91.7)$ & $3(8.3)$ \\
Open field defecation & 49 & $44(89.8)$ & $5(10.2)$ \\
Pit latrine & 150 & $135(90.0)$ & $15(10.0)$ \\
Total & & & \\
Use of antihelminthic drug & 29 & $18(62.1)$ & $11(37.9)$ \\
Yes & 121 & $117(96.7)$ & $4(3.3)$ \\
No & 150 & $135(90.0)$ & $15(10.0)$ \\
Total & & & \\
Disposal of refuse & 60 & $53(88.3)$ & $7(11.7)$ \\
Dumpsite & 80 & $74(92.5)$ & $6(7.5)$ \\
Bush & 10 & $8(80.0)$ & $2(20.0)$ \\
Burning & 150 & $135(90.0)$ & $15(10.0)$ \\
Total & &
\end{tabular}

\section{DISCUSSION}

It is interesting to note that 135 of the 150 students examined in this study were positive for one or more gastrointestinal parasites .The high prevalence of infection reported in this study demonstrated the potential burden of parasitic infections in students in this area.
This study showed that helminth infections were endemic among the post-primary students in the study area. In the schools sampled, Ascaris lumbricoides was the most common infection, followed by Strongyloides stercoralis while hookworm is the least prevalent. The endemicity of helminth infections had been reported in Nigeria. This had been attributed to the combination of hot, humid 
climate, poor sanitation and personal hygiene, ignorance and cultural practices all of which enhance multiple infections with intestinal helminths (Udonsi and Morgan, 1985). This observation was also in tandem with Crompton (1999) who said helminth infections thrive and persist in communities in need of better housing, clean water, and appropriate sanitation, better access to healthcare, education and increased personal earnings. It was observed that the predominant intestinal parasites among post primary school in Osogbo were Ascaris lumbricoides, hookworm and Strongyloides stercoralis. Surveys across the country had shown variations in the distribution of intestinal parasitic infections in Nigeria (Rufai and Awi-waadu, 2006). However, this result is largely consistent with the observation of (Adeleye et al., 2015). It is well established that the infective stages of $A$. lumbricoides have enormous capacity in withstanding environmental extremes. Furthermore, Ascaris eggs are coated with mucopolysaccharides substance which makes these eggs adhesive to different body surfaces. This accounted for their adhesiveness to books, door handles, dust, fruits and vegetables, paper money and coins. Consequently, due to poor hand washing practices and observance of personal hygiene, students inadvertently get infected through these items. The prevalence of infections was low for hookworm and Strongyloides stercoralis among the students. The presence of large numbers of adult Ascaris worms in the small intestine can cause abdominal distension and pain (Mashitani and Kitade, 2007). Prevalence of intestinal helminthes in relation to intensity of the parasite infections in the study area showed the egg number per gram faeces (EPG) of Ascaris lumbricoides to be higher (97.4\%), followed by Strongyloides stercoralis $(1.8 \%)$ while Hookworm had the least intensity.

Multiparasite combination was observed in this study with double infection involving a combination of Ascaris lumbricoides/ Strongyloides stercoralis having highest prevalence (Table 3). Udonsi et al., (1996) had reported on the triad of Hookworm-Ascaris-trichuris as common throughout much of Nigeria, combination of Ascaris lumbricoides/ Strongyloides stercoralis as observed in this study may be an indication of similar ecological requirements. Morbidity as a result of concurrent and multiple infections had been associated with anemia, stunted growth, decreased appetite, and intellectual retardation, cognitive and educational deficits (Somphou et al., 1997). These conditions in no small measure had a way of causing absenteeism from school resulting in poor academic performance (Raj et al., 1997).

Age specific prevalence of parasites showed that infection rate increased with age among students reaching the peak with 9-11year age group and sharply dropped with advancing age. This observation could probably be due to higher exposure to source of infection through their school activities since mature students were more often engaged in activities like sweeping, waste hand picking, washing toilet, gardening, and playing in the soil e.t.c that could predispose them to helminths infections. The more mature students often exempt themselves from these tasks on the pretense of seniority. However, of those infected, infection rate among female was significantly higher than males. This contradicted the findings of Rufai and Awi-waadu (2006) who recorded higher prevalence in male than females and attributed it to variations in the frequency and intensity of exposure to the contaminated areas. The high prevalence recorded among females in this study may also be due to higher exposure frequency to contaminated sites since females were engaged more in sweeping activities, toilet washing and fetching of water.

Responses of students in the study area to questionnaire administered and the results of statistical analysis in relationships with the various epidemiological variables and the helminth infections showed that students whose source of drinking water is the stream/river and whose toilet system was either open field or pit had the highest prevalence of infection while the least infection rate was observed in those using water cistern toilet. This could be due to the odoriferous nature of pit latrine and open field defecation which often attracted hundreds of rats and flies daily. These rats and flies may spread eggs of helminth parasites. The implication of rats in the transmission of helminths of public health importance was shown by Rufai and Olagunju, (2017). Prevalence in relation to the use of 
antihelminthic drugs showed that the rate of infection was higher among those students that never took anti-helminthic drugs.

\section{CONCLUSION}

There is a deficit of published data on the prevalence and intensity of intestinal parasitic infections in Osogbo. Post primary school students are at high risk of acquiring gastrointestinal parasitic infections in Osogbo as demonstrated by the exceptionally high percentage infection rate $(96.0 \%)$ in this study. A better prevalence and surveillance mapping system is therefore recommended. Mapping of the known foci of infections is necessary in order to identify populations most at risk, their location, age groups and which authority has the capacity to monitor, evaluate, and respond. This report also recommends that good drinking water coupled with adequate toilet facilities and deworming programs be integrated in private and public elementary schools as well as promotion of healthier diets as most effective tools in controlling helminth infection among students.

\section{ACKNOWLEDGEMENTS}

The authors sincerely wish to acknowledge the technical assistance from the Department of Biological Sciences, Zoology unit, Osun State University, Osogbo especially Mrs. Ogunlana as well as the co-operation from the parents, schools principals and the entire management and staff of the schools where samples were collected.

\section{FINANCIAL DISCLOSURE}

There is no financial disclosure to report. None of the authors received any financial benefit for conducting or reporting this research. All authors actively participated in the performance of the reported research.

\section{REFERENCES}

Adefioye, O.A., Efunshile, A.M, Ojurongbe, O., Akindele, A.A., Adewuyi, I.K., Bolaji, O.S., Adedokun, S.A. and Adeyeba, A.O. (2011). Intestinal Helminthiasis amongSchool Children in Illie, Osun State.Sierra Leone Journal of Biomedical Research, 3(1):36-42

Adeleke, M. A., Akatah, H. A., Hassan, A. O., SamWobo, S. O., Famodimu, T. M., Olatunde,
G. O. and Mafiana, C. F. (2012). Implication of cockroaches as vectors of gastrointestinal parasites in parts of Osogbo, Southwestern Nigeria. Munis Entomology \& Zoology, 7 (2): 1106-1110

Adeleye, A., Oluwatosin A., Adedayo, S., Olaitan, A., Donatus, S. (2015). Prevalence of helminthic infection and its association with the nutritional status of rural primary school children in Osun state. Journal of Biology, Agriculture and Healthcare, Vol. 5 no 14

Anosike, J. C., Zaccheaus, V. O., Adeiyongo, C. M., Abanobi, O. C., Dada, E. O., Oku, E. E., Keke, I. R., Uwaezuoke, J. C., Amajuoyi, O. U., Obiukwu, C. E., Nwosu, D. C. and Ogbusu, F. I.(2006) Studies on the Intestinal Worm (Helminthiasis) Infection in a Central Nigerian Rural Community. JASEM, 10 (2): 61-66.

Asaolu, S. O. and Ofoezie, I. E (2003). The role of health education and sanitation in the control of helminth infections. Acta Tropica, 86: 283-294.

Awasthi, S., Peto, R., Read, S., Clark, S., Pande, V., Bundy, D. (2013).DEVTA (Deworming and Enhanced Vitamin A) team. Vitamin A supplementation every 6 months with retinol in 1 million pre-school children in north India: DEVTA, a clusterrandomized trial. Lancet, 381(9876):14691477

Awi-Waadu, G.D.B.(2005). The prevalence of Gastrointestinal Tract Parasites in the inhabitants of Bori Military cantonment in Port Harcourt Local Government Area of Rivers State, Nigeria. African Journal of Applied Zoology and Environmental Biology, 7: 56-60

Casapia, M., Joseph, S.A., Nüñer, C., Rahme, E., Gyorkos, T.W. (2007) Parasite and maternal risk factors for malnutrition in preschool-age children in Belen, Peru using the new WHO Child Growth Standards. British Journal of Nutrition, 98: 1259-1266.

Crompton, D.W.T. (1999). How much human Helminthiasis in the world? The Journal of Parasitology, 85(3): 397-403

Damen, J. G., Luka, J. and Lugos, M. (2011).Prevalence of Intestinal Parasites 
among Pupils in Rural North Eastern, Nigeria. NigerMedJ, 52 (1), 4-6.

Fashuyi, S. A. (1983). The prevalence of helminth eggs in human faeces deposited on the streets of Lagos. West African Medical Journal, 2:135-138.

Faten, A. A. (2008). Is intestinal parasite infection still a public health concern among Saudi children. SaudiMedJ., 29 (11):1630-1635.

Ijagbone, I. F. and Olagunju, T. F. (2006).Intestinal Helminth parasites in school children in Iragbiji, Boripe Local government, Osun State. Nigeria African Biomedical Research, 9(1): 63-65.

Mafiana, C. F., Sam-Wobo, S. O. and Akinsete, A. A. (2000).Epidemiology of Ascariasis in some rural communities in Ogun State, Nigeria. Global Journal of Pure Applied Sciences, 6 (1): 23-26

Mashitani, M., T, and Kitade, T. (2007).Eosinophilic cholecystitis along with pericarditis caused by Ascaris lumbricoides: a case report. World J. Gastroenterol, 13:3760-3762.

McGregor I .A., Williams K., Brilleanien N.C and Thompson A.M.(1996).Haemoglobin concentration and anaemia in young West African Children. Trans Roy. Soc. Trop. Med. Hyg., 60: 650-67.

Montressor, A., Crompton, D. W., Gyorkos, T. W. and Savioli, L. (2002). Helminth control in school-age children. A guide for managers of control programmes. World Health Organisation, Geneva 64 pages.

Odutan, S .O., (1974).The health of Nigerian children of school age (6-15years) II.Parasitic and infective conditions, the special senses, physical abnormalities. Annals of Tropical Medicine and Parasitology, 68:145-156.

Ogbe, M. G., Edet, E. and Isichei, M. N. (2002). Intestinal helminth infection in primary school children in areas of operation of Shell Petroleum Development Company of Nigeria (SPDC), Western Division in Delta State, Nigeria. Nigerian Journal of Parasitology, 23: 3-10.

Omorodion, O.A., Isaac, C., Nmorsi, O.P.G., Ogoya, E.M. and Agholor, K.N. (2012), Prevalence of intestinal parasitic infection among tertiary institution students and pregnant women in south-south, Nigeria J. Microbiol. Biotech. Res., 2(5):815-819

Raj, S.M, Sein, K.T., Anuar, A.K. and Mustaffa, B. E. (1997) Effect of intestinal helminthiasis on school attendance by early primary schoolchildren. Trans. R. Soc. Trop. Med. Hyg. 91:131-132.

Rufai, A.M. and Awi - Waadu, G.D.B. (2006) Prevalence of Human Gastro-intestinal parasitic infections in relation to Human and Industrial activities in Rumuolumeni community in Rivers State, Nigeria. African Journal of Applied Zoology and EnvironmentalBiology. 8:62-66.

Rufai, A.M. and Olagunju, R.O. (2017). Implication of Rattus rattus as vectors of gastrointestinal helminthes parasites in parts of Osogbo, Southwestern Nigeria., $J$. of Advanced Botany and Zoology, V5I1. DOI: 10.15297/JALS.V5I1.04

Sam-Wobo, S. O., Oyeyemi, O. A., Idowu, O. A. and Afolarin, A. (2006). Assessment of health knowledge and risk factors associated with intestinal helminthes in tertiary schools in Abeokuta, Nigeria. Nigerian Journal of Parasitology, 27: 76-80

Somphou, S., Jürg, U., Kongsap, A. and Peter, O. (2015). Multiparasitism and intensity of helminth infections in relation to symptoms and nutritional status among children: A cross-sectional study in southern Lao People's Democratic Republic, Acta Tropica, 141, 322-331

Teklu, W., Tsegaye, T., Belete, S. and Takele, T. (2013). Prevalence of intestinal parasitic infections among highland and lowland dwellers in Gamo area, South Ethiopia BMC Public Health, ISSN: 1471-2458

UNDP (2006).Unsatisfied Basic Needs Mapping and. Living Standards in Iraq. The Republic of Iraq Ministry of Planning and Development Cooperation, Central Organization for Statistics and InformationTechnology.

Udonsi, J.K., Behnke, J.M. and Gilbert, F.S. (1996): "Analysis of the prevalence of infection and associations between human gastrointestinal nematodes among different age classes living in the urban and sub-urban communities of Port Harcourt, Nigeria. J. Helminthol, 70: 75-84. 
626 Mohammed et al.: Studies on the Prevalence and Intensities of Gastrointestinal Helminths Infections

WHO (1991).World Health Organization Basic laboratory methods in medical parasitology. Geneva, Switzerland.

WHO (1996): Strengthening interventions to reduce helminths infections: An entry point for the development of health promoting schools WHO/ HPR/HEP/96.1 